\title{
TINGKAT KEPUASAN PELANGGAN TERHADAP SISTEM PELAYANAN FARMASI DI APOTEK KIMIA FARMA 274 PAMEKASAN
}

\section{LEVEL OF CUSTOMER SATISFACTION ON PHARMACEUTICAL SERVICE SYSTEM IN KIMIA FARMA 274 PHARMACY PAMEKASAN}

\author{
Achmad Faruk Alrosyidi ${ }^{1 *}$, Fauzan Humaidi ${ }^{1}$, Iffah Wulandari Aprilia ${ }^{1}$ \\ ${ }^{1}$ Program Studi DIII Farmasi Universitas Islam Madura \\ "Corresponding Author Email: faruk.alrosyidi@gmail.com \\ DOI: http://dx.doi.org/10.47653/farm.v7i1.155
}

\begin{abstract}
ABSTRAK
Apotek harus berpedoman pada standar pelayanan yang berlaku dalam melaksanakan praktek pelayanan kefarmasian. Pelayanan kefarmasian mengalami perubahan yang semula hanya berfokus pada pengolahan obat (drug oriented) menjadi pelayanan yang komprehensif (pharmaceutical care) yaitu pelayanan yang langsung dan bertanggung jawab kepada pasien yang berkaitan dengan sediaan farmasi. Penelitian ini bertujuan untuk mengetahui tingkat kepuasan pelanggan terhadap sistem pelayanan kefarmasian di apotek Kimia Farma 274 Pamekasan. Penelitian ini merupakan penelitian deskriptif kuantitatif menggunakan kuisioner dengan skala Likert. Hasil dari penelitian yang dilakukan kepada 100 responden menunjukkan bahwa pelanggan apotek kimia farma 274 Pamekasan merasa sangat puas terhadap lokasi dan tata ruang apotek, ketersediaan perbekalan farmasi, waktu pelayanan, dan sikap tenaga kefarmasian dalam melakukan pelayanan kefarmasian. Hasil penelitian ini dapat digunakan sebagai bahan evaluasi terhadap apotek agar dapat meningkatkan pelayanan kefarmasian dimasa yang akan datang dan pemacu sarana pelayanan kefarmasian yang lain untuk memberikan pelayanan kefarmasian yang lebih baik lagi kepada pelanggan.
\end{abstract}

Kata Kunci: Apotek, Kimia Farma 274 Pamekasan, Kepuasan Pelanggan, Pelayanan Kefarmasian

\begin{abstract}
Pharmacies must be guided by applicable service standards in carrying out pharmaceutical service practices. Pharmaceutical services underwent a change that initially only focused on drug (drug oriented) into a comprehensive service (pharmaceutical care) that is a direct and responsible service to patients relating to pharmaceutical preparations. This study aims to determine the level of customer satisfaction with the pharmaceutical service system at the Kimia Farma 274 Pharmacy Pamekasan. This research is a quantitative descriptive study using a questionnaire with a Likert scale. The results of research conducted to 100 respondents showed that customers of Kimia Farma 274 Pharmacy Pamekasan were very satisfied with the location and layout of the pharmacy, the availability of pharmaceutical supplies, time of service, and the attitude of pharmaceutical personnel in conducting pharmaceutical services. The results of this study can be used as an evaluation for pharmacies in order to improve pharmacy services in the future and trigger other pharmaceutical service facilities to provide better pharmaceutical services to customers.
\end{abstract}

Keywords: Pharmacy, Kimia Farma 274 Pamekasan, Customer Satisfaction, Pharmaceutical Services

\section{PENDAHULUAN}

Dalam penyelenggaraan standar pelayanan kefarmasian di apotek harus didukung oleh ketersediaan sumber daya kefarmasian yang berorientasi kepada keselamatan pasien. Adapun sumber daya yang dimaksud meliputi sumber daya manusia seperti apoteker dan TTK (Tenaga Teknis
Kefarmasian) yang profesional, sarana dan prasarana seperti lokasi yang mudah di jangkau dan sebagainya. Selain itu penyelenggaraan pelayanan kefarmasian di apotek harus menjamin ketersediaan sediaan farmasi, alat kesehatan, dan bahan medis habis pakai yang aman, bermutu, bermanfaat, dan terjangkau (Permenkes RI,2016). 
Standar pelayanan kefarmasian pada saat ini telah bergeser orientasinya dari drug oriented ke patient oriented yaitu kegiatan pelayanan kefarmasian yang semula hanya berfokus pada pengelolaan obat sebagai komoditi menjadi pelayanan yang langsung dan bertanggung jawab kepada pasien yang berkaitan dengan sediaan farmasi dengan maksud mencapai hasil yang pasti untuk meningkatkan mutu kehidupan pasien.

Adapun pengertian standar pelayanan kefarmasian adalah tolak ukur yang dipergunakan sebagai pedoman bagi tenaga kefarmasian dalam menyelenggarakan pelayanan kefarmasian guna menghindari kemungkinan terjadinya kesalahan pengobatan dalam proses pelayanan. Selanjutnya untuk mengetahui keberhasilan pelayanan kefarmasian di apotek adalah dengan penilaian kepuasan pelanggan, karena penilaian kepuasan pelanggan dianggap sebagai penunjuk utama dari kualitas layanan farmasi yang diterima oleh pelanggan dan akan menjadi petunjuk apakah layanan tersebut memenuhi standar atau harapan pelanggan (Peter dkk.,2017).

Kepuasan tercapai apabila jasa dan produk yang dipilih dapat memenuhi atau melebihi harapan pelanggan karena pelayanan yang berbeda akan memberikan dampak yang sangat berarti bagi suatu apotek oleh karena itu penulis melakukan penelitian dalam bentuk kuisioner sebagai tolak ukur untuk mengetahui tingkat kepuasan pasien (Narendra dkk., 2017).

Beberapa penelitian sebelumnya menunjukkan bahwa konsumen kurang atau cukup puas tepatnya di bawah kategori puas terhadap pelayanan kefarmasian di apotek penilaian kepuasan tersebut dilihat dari segi kelengkapan obat, tanggapan dari petugas apotek atas pertanyaan konsumen mengenai obat-obatan yang mereka dapatkan atau kurangnya pengetahuan, ketrampilan, dan perilaku pelayanan petugas apotek dalam memberikan layanan pengobatan (Yulia dkk.,2016; Bertawati, 2013; Sukamto, 2017).

Sampai saat ini belum pernah dilakukan penelitian tentang tingkat kepuasan pasien di
Apotek Kimia Farma 274 pamekasan. Selain itu ada sedikitnya pelanggan yang pernah mengeluh atau komplain terhadap pelayanan yang pernah diberikan baik tentang lamanya waktu pelayanan maupun tentang harga. Dalam hal ini peneliti bermaksud ingin mengukur tingkat kepuasan konsumen terhadap sistem pelayanan kefarmasian yang diberikan oleh Apotek Kimia Farma 274 Pamekasan sebagai bahan evaluasi terhadap apotek agar dapat meningkatkan pelayanan kefarmasian dimasa yang akan datang. Disamping itu kepuasan pelanggan yang belum tercapai, seharusnya menjadi fokus penting bagi manajemen apotek untuk mengambil kebijakan dalam rangka memperbaiki kualitas pelayanan di apotek (Mas`ud, 2009).

\section{METODOLOGI PENELITIAN}

Jenis penelitian yang digunakan dalam penelitian ini adalah non eksperimental dengan metode deskriptif dengan kuisioner. Penelitian ini dilaksanakan pada bulan Juni 2019 di Apotek Kimia Farma 274 Pamekasan.

Kuisioner yang digunakan dalam penelitian ini adalah kuesioner dengan model Skala Likert. Skala likert dibuat dalam bentuk ceklist dengan rating scale dengan skoring 1 sampai 5 , yaitu skor $5=$ sangat puas, skor $4=$ puas, skor $3=$ cukup puas, skor $2=$ kurang puas, skor $1=$ sangat tidak puas. Rumus yang digunakan dalam menentukan tingkat kepuasan pasien/pelanggan adalah sebagai berikut:

$$
\text { Kepuasan Pasien (\%) }=\frac{\text { Jumlah Skor Penelitian }}{\text { Skor Ideal (kriterium) }} \times 100 \%
$$

Tingkat kepuasan pasien ditentukan dengan melihat nilai persentase Kepuasan Pasien sebagai berikut: Sangat tidak puas = $0 \%-20 \%$, Kurang Puas $=21 \%-40 \%$, Cukup puas $=41 \%-60 \%$, Puas $=61 \%-80 \%$, dan Sangat puas $=81 \%-100 \%$.

Jumlah sampel dalam penelitian ini menggunakan rumus Slovin (Sugiyono, 2011).

Tabel 1. Tingkat Kepuasan Pelanggan Apotek

\begin{tabular}{|c|c|c|c|}
\hline No & Indikator Pelayanan & Kepuasan Pasien n=100 (\%) & Klasifikasi \\
\hline 1 & Kestrategisan dan Kemudahan Lokasi Apotek Untuk Dijangkau & 89 & Sangat Puas \\
\hline 2 & Kebersihan, Kerapian, dan Kenyamanan Apotek & 93 & Sangat Puas \\
\hline 3 & Kelengkapan Obat-obatan di Apotek & 85 & Sangat Puas \\
\hline 4 & Kecepatan Pelayanan Obat & 85 & Sangat Puas \\
\hline 5 & Keramahan dan Kesopanan Petugas Apotek & 90 & Sangat Puas \\
\hline 6 & Kecepatan Pelayanan Apotek & 91 & Sangat Puas \\
\hline
\end{tabular}


Rumus Slovin untuk menentukan sampel adalah sebagai berikut :

$$
\mathrm{n}=\frac{\mathrm{N}}{1+\mathrm{Ne}^{2}}
$$

Keterangan:

$\mathrm{n}=$ Ukuran sampel/jumlah responden

$\mathrm{N}=$ Ukuran populasi

$\mathrm{e}=$ Presentase kelonggaran ketelitian

kesalahan pengambilan sampel yang

masih bisa ditolerir; $e=0,1$

Besar populasi penelitian 2.967 orang diambil dari rata-rata kunjungan pada bulan maret, april dan mei tahun 2019. Sehingga jumlah sampel penelitian adalah 100 orang. Sampel yang dipilih adalah pelanggan Apotek Kimia Farma 274 Pamekasan yang memenuhi kriteria inklusi. Kriteria inklusi dalam penelitian ini adalah pelanggan dengan usia 17-70 tahun, besedia mengisi kuisioner, menebus resep atau membeli obat untuk pengobatan sendiri (swamedikasi), tingkat pendidikan minimal SMA agar responden memiliki pemahaman yang baik akan pertanyaan-pertanyaan yang diajukan di kuesioner.

\section{HASIL DAN PEMBAHASAN \\ Karakteristik Responden}

Deskripsi karakteristik responden akan memberikan gambaran mengenai identitas responden dalam penelitian ini. Tingkat kepuasan responden dapat dipengaruhi oleh faktor-faktor seperti jenis kelamin, umur, pendidikan, dan pekerjaan (Bahem,2017). Deskripsi karakteristik responden penelitian ini dapat dikelompokkan menjadi empat yaitu jenis kelamin, umur, pekerjaan dan pendidikan seperti pada tabel 2.

Tabel 2. Karakteristik Responden

\begin{tabular}{lllc}
\hline No & & Karakteristik & $\begin{array}{c}\text { Persentase } \\
\text { (\%) }\end{array}$ \\
\hline 1. & Jenis Kelamin & a. Laki-laki & 63 \\
& \multirow{2}{*}{ 2. Usia } & b. Perempuan & 37 \\
& & a. 17-30 tahun & 38 \\
3. & b. 31-50 tahun & 42 \\
& Pendidikan & c. 50-70 tahun & 20 \\
& a. SLTA & 54 \\
4. & Pekerakhir & b. Diploma & 7 \\
& & C. Sarjana & 39 \\
& & a. PNS & 28 \\
& & b. Swasta & 6 \\
& & c. Wiraswasta & 40 \\
& & d. Pelajar & 6 \\
& & e. Ibu rumah tangga & 12 \\
& & f. Pensiunan /lain- & 8 \\
\hline
\end{tabular}

Responden laki-laki lebih banyak dibandingkan dengan responden perempuan. Responden paling sedikit berumur antara 5070 tahun sebanyak 20 orang karena pada umumnya pelanggan dengan umur di atas 50 tahun kondisi fisik mulai menurun dan cenderung menyuruh keluarganya untuk menebus/membeli obat ke apotek.

Selain usia, pendidikan juga merupakan faktor yang berpengaruh terhadap persepsi seseorang dalam menilai sesuatu, karena pendidikan menunjukkan tingkat pendidikan dan intelektual seseorang. jika dilihat berdasarkan pendidikan terakhir, responden paling banyak adalah lulusan SLTA dengan jumlah 54\%. Sedangkan karakteristik responden berdasarkan jenis pekerjaan didominasi oleh wiraswasta sebanyak $40 \%$.

\section{Tingkat Kepuasan Responden terhadap Lokasi dan Tata Ruang Apotek}

Tanggapan responden untuk pernyataan kestrategisan dan kemudahan lokasi apotik untuk dijangkau responden memberikan penilaian sangat puas. Hal tersebut dikarenakan letak apotek yang dekat dengan pusat kota sehingga dijangkau oleh masyarakat Kota Pamekasan. Ada 3 orang responden menjawab tidak puas, hal ini karena area parkir yang kurang luas sehingga pelanggan sedikit kesulitan dalam memarkir kendaraannya.

Responden memberikan penilaian sangat puas untuk kebersihan, kerapian, dan kenyamanan apotek. Hal ini dikarenakan layout apotek kimia farma 274 pamekasan yang sudah ditentukan sedemikian rupa demi kenyamanan pelanggan seperti adanya swalayan apotek sehingga pelanggan bebas memilih apa yang dibutuhkan, penerangan yang baik, adanya musik, ruang tunggu yang disertai $A C$, kebersihan yang selalu dijaga dan pegawai yang ramah. Akan tetapi ada beberapa responden menjawab cukup puas, hal ini dikarenakan kurangnya fasilitas diruang tunggu seperti televisi sehingga pasien sedikit merasa bosan pada saat menunggu resep yang ditebus. Tingkat kepuasan responden terhadap kestrategisan dan kemudahan lokasi apotek dapat dilihat pada Gambar 1. Sedangkan Tingkat kepuasan responden terhadap kebersihan, kerapian, dan kenyamanan apotek dapat dilihat pada Gambar 2. 


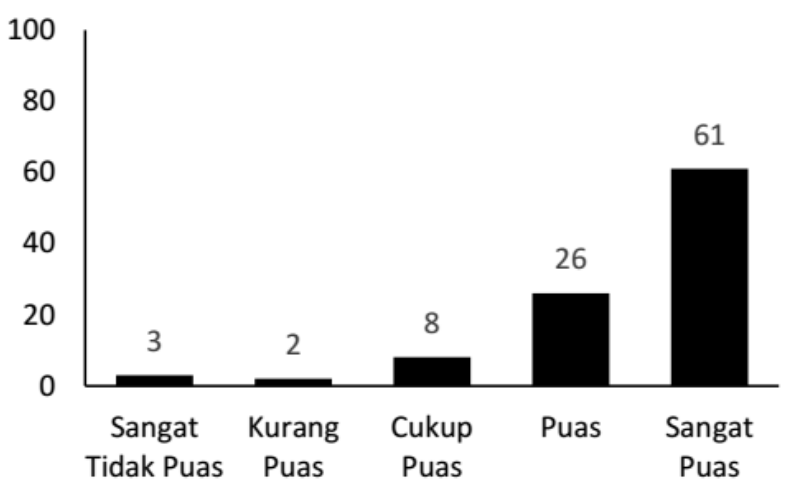

Gambar 1. Tingkat Kepuasan Responden Terhadap Kestrategisan dan Kemudahan Lokasi Apotek

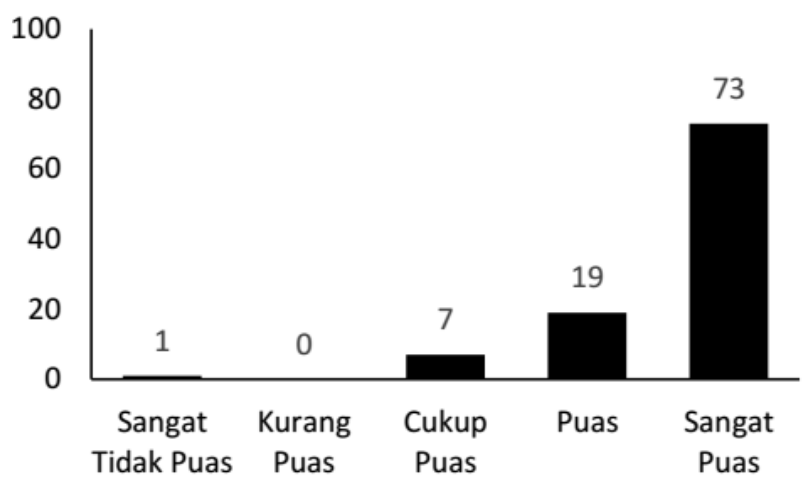

Gambar 2. Tingkat Kepuasan Responden Terhadap Kebersihan, Kerapian, Dan Kenyamanan Apotek

\section{Tingkat kepuasan Responden terhadap Ketersediaan Perbekalan Farmasi}

Parameter kelengkapan obat-obatan di apotek digunakan untuk mengetahui tingkat kepuasan responden terhadap ketersediaan perbekalan farmasi di apotek kimia farma 274 pamekasan. Dari parameter tersebut dapat di ketahui bahwa responden memberikan penilaian sangat puas, karena setiap pelanggan yang masuk di apotek kimia farma 274 pamekasan diusahan keluar tanpa rasa kecewa karena setiap petugas di wajibkan memberikan solusi bagi pelanggan, misalkan obat yang dibutuhkan pelanggan kebetulan tidak ada maka bisa disubstitusi dengan merk lain dengan mengkonfirmasi dahulu kepada dokter penulis resep atau pasien yang bersangkutan atau di pesankan ke outlet kimia farma yang lain.

Akan tetapi ada empat responden menjawab kurang puas dikarenakan resep yang ditebus jumlahnya ada yang kurang dan juga karena waktu yang dijanjikan/ dipesankan buat obat yang kosong kadang agak lama karena kendala pengiriman antar outlet kimia farma dari luar daerah. Tingkat kepuasan responden terhadap kelengkapan obat-obatan di apotek dapat dilihat pada Gambar 3.

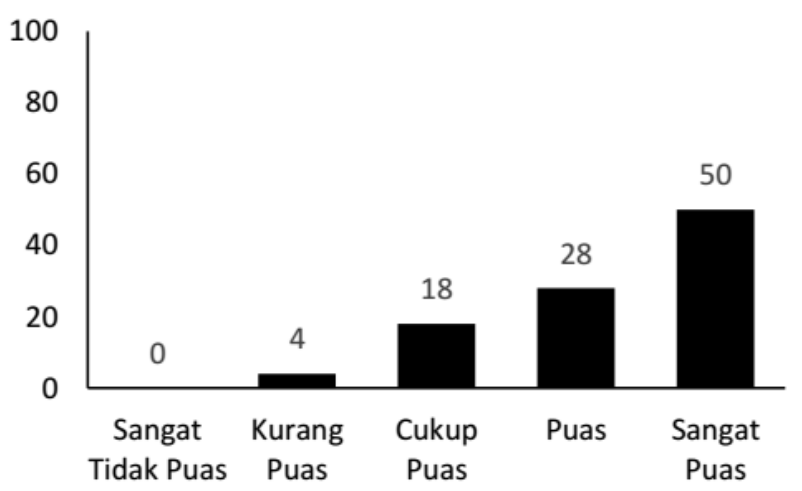

Gambar 3. Tingkat Kepuasan Responden Terhadap Kelengkapan Obat-Obatan Di Apotek

\section{Tingkat kepuasan Responden terhadap Waktu Pelayanan}

Kecepatan pelayanan obat non racikan atau swamedikasi adalah kurang dari 15 menit sedangkan waktu tunggu obat racikan adalah kurang dari 30 menit. Tingkat kepuasan responden terhadap waktu pelayanan tergolong sangat puas. Hal ini dikarenakan di apotek kimia farma 274 pamekasan mempunyai Standart Operational Procedure (SOP) untuk waktu pelayanan yakni maksimal 15 menit untuk pelayanan non resep dan resep non racikan sedangkan maksimal 30 menit untuk resep racikan. Tingkat kepuasan responden terhadap kecepatan pelayanan obat non racikan atau swamedikasi.

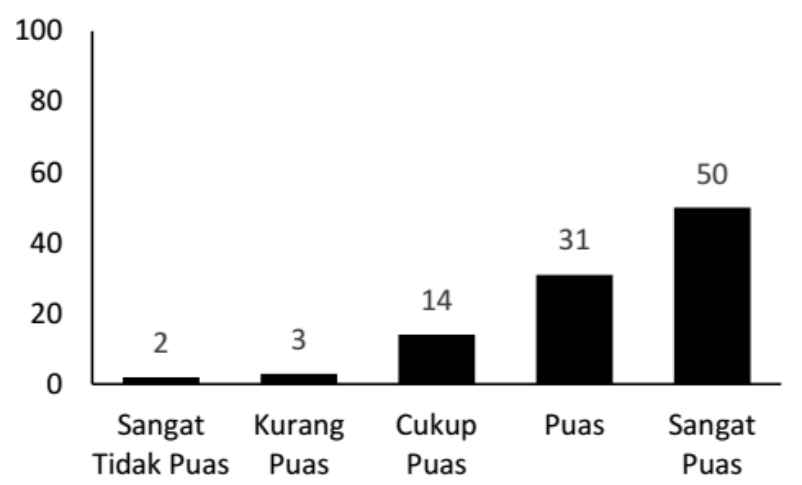

Gambar 4. Tingkat Kepuasan Responden Terhadap Kecepatan Pelayanan Obat Non Racikan atau Swamedikasi

\section{Tingkat Kepuasan Responden terhadap Sikap dan Pelayanan Tenaga Kefarmasian}

Persentase Tingkat kepuasan pelanggan terhadap keramahan dan kesopanan petugas 
apotek, kecepatan pelayanan apotek, pemberian onformasi yang jelas dan lengkap tentang informasi obat serta ketersediaan karyawan menjawab pertanyaan konsumen dapat dilihat di gambar 5, gambar 6, gambar 7 , dan gambar 8 .

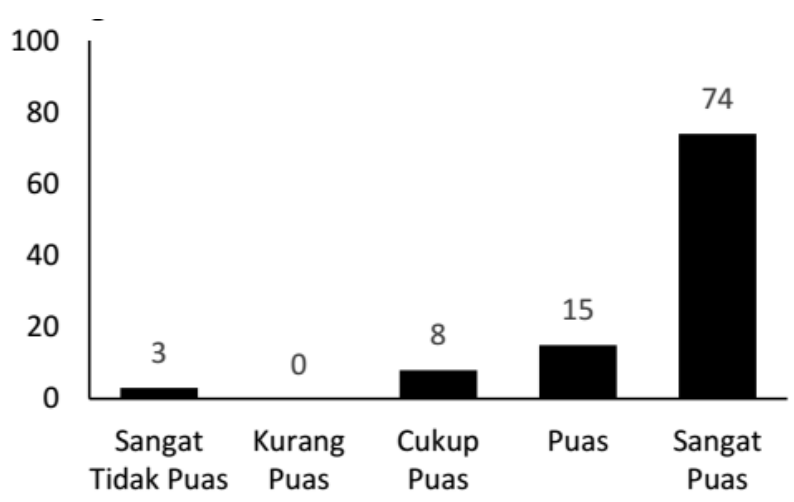

Gambar 5. Tingkat Kepuasan Responden

Terhadap Keramahan dan Kesopanan Petugas Apotek

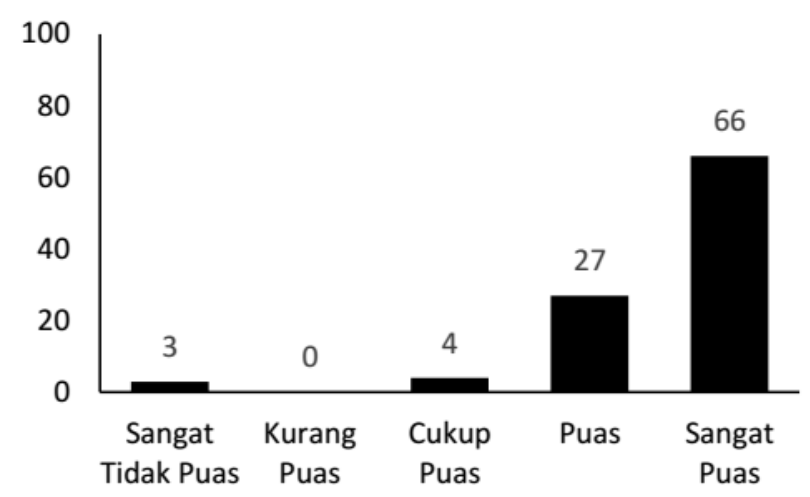

Gambar 6. Tingkat Kepuasan Responden

Terhadap Kecepatan Pelayanan Apotek

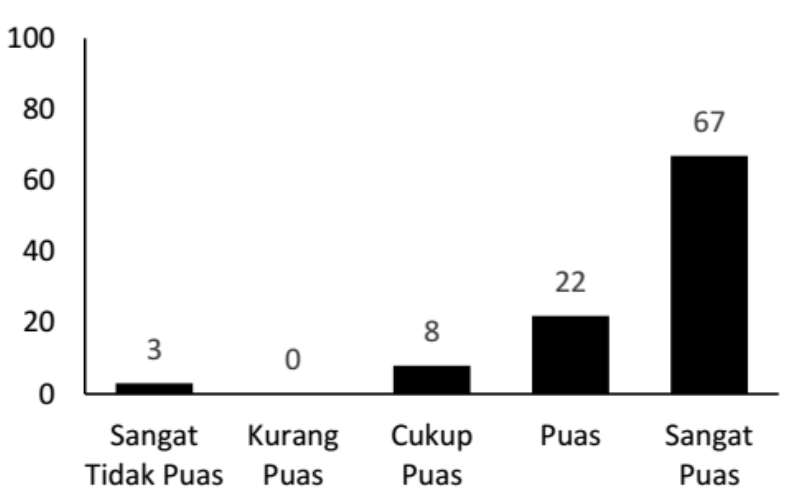

Gambar 7. Tingkat Kepuasan Responden Terhadap Pemberian Informasi Yang Lengkap dan Jelas Tentang Obat

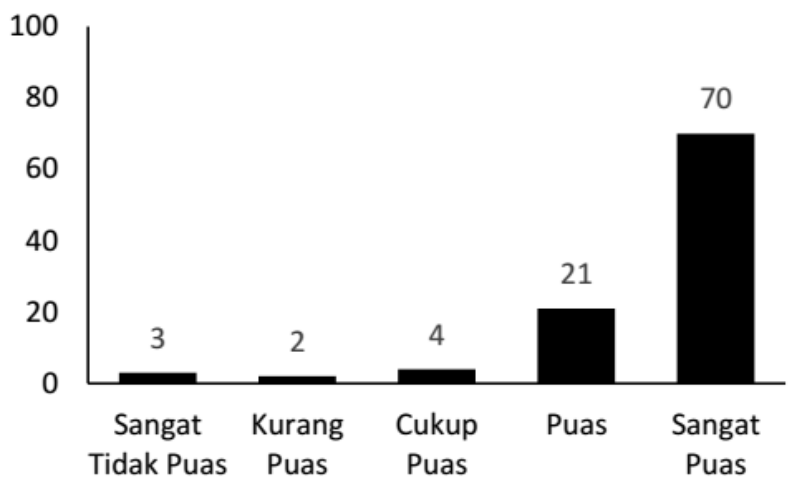

Gambar 8. Tingkat Kepuasan Responden Tentang Ketersediaan Karyawan Untuk Menjawab Pertanyaan Konsumen

Secara keseluruhan tingkat kepuasan pasien terhadap sikap dan pelayanan tenaga kefarmasian adalah sangat puas. Hal ini disebabkan karena Kimia Farma memberikan pelatihan bagi karyawannya untuk memberikan pelayanan yang baik bagi konsumen. Selain itu Kimia Farma juga mempunyai SOP mengenai pelayanan yang mendukung agar konsumen merasa puas terhadap pelayanan yang diberikan apotek.

\section{KESIMPULAN}

Berdasarkan hasil penelitian dapat disimpulkan bahwa pelanggan Apotek Kimia Farma 274 Pamekasan sangat puas terhadap lokasi dan tata ruang apotek, ketersediaan perbekalan farmasi, waktu pelayanan, dan sikap tenaga kefarmasian dalam pelayanan. Jadi tingkat kepuasan pelanggan terhadap sistem pelayanan kefarmasian di Apotek Kimia Farma 274 Pamekasan secara keseluruhan adalah sangat memuaskan yang artinya pelayanan kefarmasian yang diberikan oleh petugas apotek kimia farma 274 Pamekasan kepada pelanggan sudah baik dan sesuai dengan apa yang diharapkan oleh konsumen.

\section{DAFTAR PUSTAKA}

Bertawati. 2013. Profil Pelayanan Kefarmasian Dan Kepuasan Konsumen Apotek Di Kecamatan Adiwerna Kota Tegal. Calyptra. Jurnal IImiah Mahasiswa Universitas Surabaya, 2 (2): 1-11.

Mas'ud. 2009. Analisis Tingkat Kepuasan Pelanggan Terhadap Pelayanan Apotek Kimia Farma Jakarta Menggunakan Model Servqual (studi Kasus Pada Tiga Apotek). Pharmaceutical Sciences and Research (PSRI), 6 (2): 56-74.

Narendra, M.P., Skarayadi, O., Duda. M., Adirestuti, P. 2017. Analisis Tingkat 
Kepuasan Pelanggan Terhadap

Pelayanan Di Apotek Kimia Farma Gatot Subroto Bandung. Kartika-Jurnal IImiah Farmasi, 5(1): 31-37.

Permenkes. 2016. Peraturan Menteri Kesehatan Republik Indonesia Nomor 73 Tahun 2016 Tentang Standar Pelayanan Kefarmasian di Apotek. Jakarta: Kementerian Kesehatan Republik Indonesia.

Peter, O.A., Joshua, E..F., Daughter, O.A.E., Nelson, E.C. 2017. Assessment of Patient Satisfaction with Pharmaceutical Services In A Hospital In Bayelsa State SouthSouth Of Nigeria. Ortho \& Rheum Open Access J, 6(3): 1-7.
Sugiyono. 2011. Metode Penelitian Kuantitatif, Kualitatif dan R\&D. Bandung: Alfabeta.

Sukamto. 2017. Evaluasi Kepuasan Pasien Terhadap Pelayanan Kefarmasian Di Apotek Rawat Jalan RSUP Dr. Wahidin Sudirohusodo Kota Makassar. Skripsi. Fakultas Kedokteran dan IImu Kesehatan.

Yulia, P.M., Baga, L.M., Djohar, S. 2016. Kepuasan Konsumen TerhadapPelayanan Apotek Dan Tingkat Pengetahuan Konsumen Mengenai Standar Pelayanan Kefarmasian Yang Berlaku (Studi Kasus Di Kota Depok). Jurnal Aplikasi Bisnis dan Manajemen, 2 (3): 302-322. 